\title{
Epistaxis Secondary to Middle Ear Pathology: A Unique Presentation
}

\author{
${ }^{1}$ Ehrlson de Sousa, ${ }^{2}$ Govind Bhuskute, ${ }^{3}$ Joevito Furtado
}

\begin{abstract}
Epistaxis is one of the most common presentations in the ear, nose, and throat (ENT) department. Majority of causes are due to local pathology, while a few are caused due to systemic causes. Epistaxis secondary to ear pathology is virtually unheard of. We report a unique case of epistaxis secondary to middle ear pathology.
\end{abstract}

Keywords: Epistaxis, Eustachian tube, Middle ear.

How to cite this article: de Sousa E, Bhuskute G, Furtado J. Epistaxis Secondary to Middle Ear Pathology: A Unique Presentation. Clin Rhinol An Int J 2017;10(3):147-149.

\section{Source of support: Nil}

Conflict of interest: None

\section{INTRODUCTION}

Epistaxis simply known as nose bleeding presents as bleeding from the nasal cavity, which is noticed when blood flows out through nostrils. Nasal bleeding may occur due to nasal cavity and sinus disease, nasopharyngeal lesions, cavernous sinus lesions, rupture of artery, and false aneurysm. Some systemic diseases can also cause nasal bleeding. We describe an uncommon cause of epistaxis in this report and discuss the imaging findings and treatment course of our patient.

\section{CASE REPORT}

A 17-year-old girl presented to our hospital's emergency room with bilateral active epistaxis since 1 day. Initially, bleeding was intermittent and stopped on its own, but later she had an episode of profuse, unprovoked bleeding that lasted for an hour prior to hospital visit. On further questioning, patient gave a history of upper respiratory tract infection since the past 1 week.

Patient did not have any comorbid conditions, bleeding manifestations, or history of any drug intake.

On general examination, patient was afebrile, had a pulse rate of 100 beats per minute, regular, and respiratory

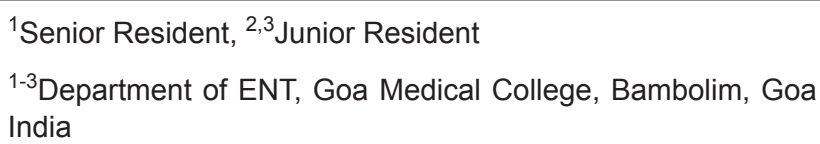

Corresponding Author: Ehrlson de Sousa, Senior Resident Department of ENT, Goa Medical College, Bambolim, Goa, India Phone: +918322495323, e-mail: ehrl218@gmail.com rate of 17 breaths per minute. She had no visible pallor, icterus, cyanosis, clubbing, or any enlarged lymph nodes.

Systemic examination including cardiorespiratory system was within the normal limits.

The ENT examination revealed bilateral active epistaxis with active postnasal bleeding. No mass or bleeding point was visualized on anterior rhinoscopy. Patient was then immediately started on procoagulants, i.e., Tranexamic acid, $500 \mathrm{mg}$ intravenous (IV) 8 hourly and Ethamsylate $500 \mathrm{mg}$ IV 8 hourly along with antibiotics and decongestant nasal drops after which bleeding stopped.

Interestingly, on otoscopic examination patient had a right-sided hemotympanum.

Routine blood workup at admission revealed normal parameters. The hemoglobin, however, dropped from 11 to $9 \mathrm{gm} / \mathrm{dL}$ following the bouts of epistaxis necessitating the need for 2 pints of blood transfusion.

Patient had no further episodes of epistaxis and was taken for a diagnostic nasal endoscopy which showed normal nasal and nasopharyngeal anatomy with no bleeding points nor any mass within.

A high-resolution computed tomography of temporal bone and magnetic resonance scan of brain and temporal bone was performed, which revealed a dehiscent right carotid canal and an enlarged right-sided jugular bulb with dehiscence of the anterior bony wall of right jugular fossa (Figs 1 and 2). There was a $4 \mathrm{~mm}$ rounded soft

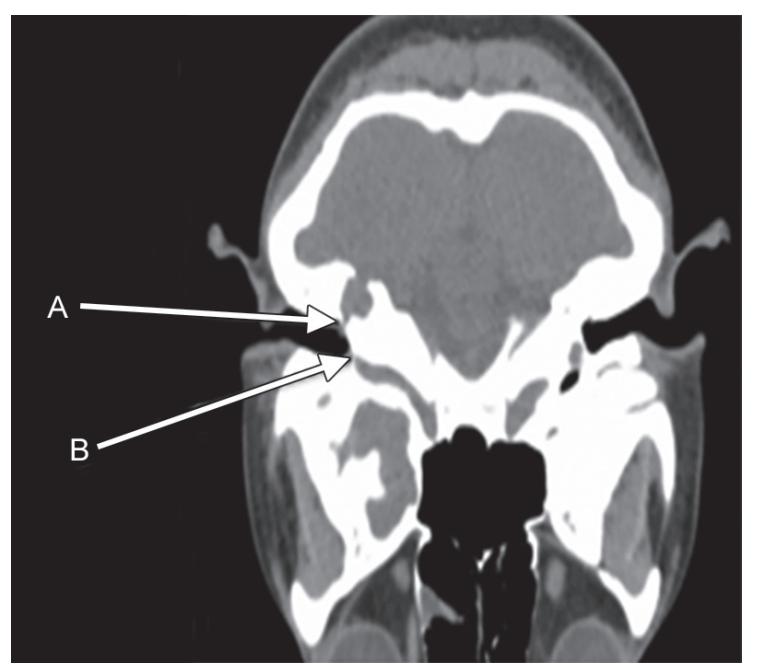

Figs $1 \mathrm{~A}$ and $\mathrm{B}$ : (A) Dehiscent anterior wall of right tympanic cavity showing exposed internal carotid artery. (B) Dehiscent right posterior and inferior wall of tympanic cavity showing enlarged jugular bulb 


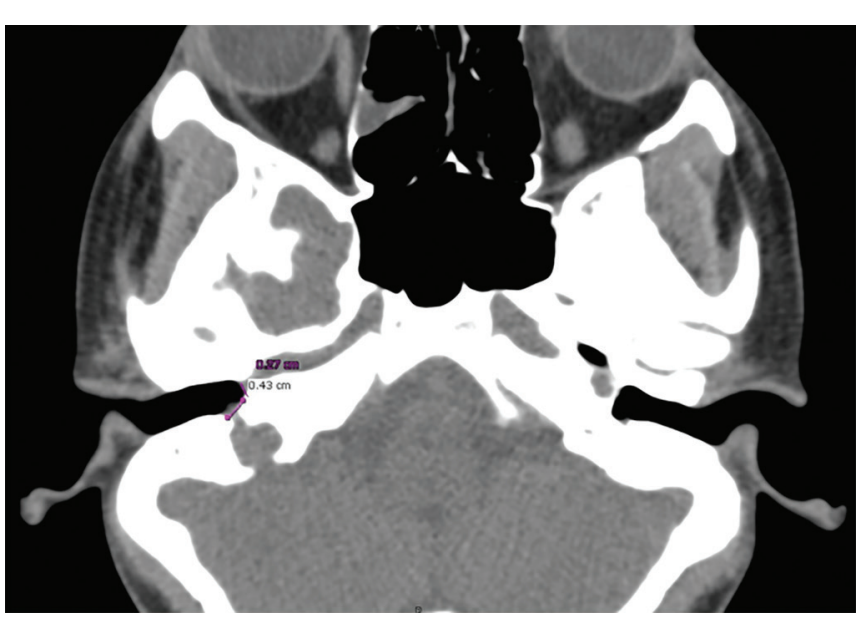

Fig. 2: Measurements of dehiscence, $0.43 \mathrm{~cm}$ on the posteroinferior wall and $0.27 \mathrm{~cm}$ on the anterior wall of tympanic cavity

tissue mass in right middle ear (posterosuperior aspect of mesotympanum) displacing the vertical portion of the right facial canal laterally, which gave a hyperintense signal on T1- and T2-weighted sequences.

A digital subtraction angiography of the carotid and vertebral system revealed asymmetrically enlarged right sigmoid sinus and jugular bulb.

Following conservative management and imaging studies, patient had no further episodes of epistaxis. She was followed up for 6 months during which time she was asymptomatic, while the right ear hemotympanum had resolved by 3 weeks following her admission.

\section{DISCUSSION}

Nasal bleeding is a common medical problem, and the cause of nasal bleeding may be due to local causes (trauma, inflammation, nasal septum disease, tumor, foreign bodies, etc.) or due to systemic causes (cardiovascular disease, blood diseases, acute febrile diseases and severe nutritional disorders and vitamin deficiency, drug poisoning, endocrine disorders, vascular dilatation disease, liver and kidney chronic disease). Coagulation deficits, Osler-Weber-Rendu disease, and arteriosclerotic vascular diseases are other possible systemic factors. ${ }^{1,2}$ In $90 \%$ of cases bleeding occurs from Little's area. ${ }^{3}$

Children have mild anterior nasal bleeding while elderly have profuse posterior nasal bleeding. Bleeding site may be (1) above the level of middle turbinate from anterior and posterior ethmoidal branches of ophthalmic artery (branch of internal carotid artery); (2) below the level of middle turbinate from sphenopalatine branch of maxillary artery (branch of external carotid artery); (3) sometimes bleeding site may be hidden in middle and inferior turbinates. ${ }^{4}$

Approximately $60 \%$ of population suffer from nasal bleeding, about $6 \%$ require formal medical intervention for those episodes of epistaxis, while $10 \%$ can be serious and life-threatening. ${ }^{5}$

Males are affected more than females, but after the age of 50 both sexes are affected equally. Hypertension is the most common cause in the elderly population. ${ }^{4}$

Hemotympanum refers to the presence of blood in the tympanic cavity of the middle ear. Temporal bone fractures, nasal packing, anticoagulant therapy, chronic otitis media, and coagulation deficits are the commonest causes of hemotympanum. ${ }^{6-8}$ It is most often associated with temporal traumas rather than nasal packing, ${ }^{9}$ but occasionally nasal packing, which can lead to peritubal lymphatic stasis, is a cause of hemotympanum. ${ }^{10}$ Dysfunction of the Eustachian tube is thought to be the reason for spontaneous hemotympanum secondary to epistaxis. ${ }^{9}$

The functions of the Eustachian tube are as follows ${ }^{11}$ :

- Pressure equalization and ventilation of the middle ear,

- Mucociliary clearance of secretions from the middle ear,

- Protection of the middle ear from sounds, from pathogens, and secretions from the nasopharynx.

Eustachian tube dysfunction is defined by symptoms and signs of pressure dysregulation in the middle ear. ${ }^{12}$

There are three subtypes of Eustachian tube dysfunction ${ }^{12}$ :

1. Dilatory Eustachian tube dysfunction,

2. Baro-challenge-induced Eustachian tube dysfunction,

3. Patulous Eustachian tube dysfunction.

Dilatory Eustachian tube dysfunction can be broken down as follows ${ }^{12}$ :

- Functional obstruction,

- Dynamic dysfunction (muscular failure),

- Anatomical obstruction.

Acute dilatory Eustachian tube dysfunction is often preceded by an upper respiratory tract infection, or sometimes by an exacerbation of allergic rhinitis, which presumably causes inflammation in the Eustachian tube orifice or lumen.

We present a unique case wherein middle ear pathology, i.e., otitis media, which was precipitated by upper respiratory infection resulted in profuse bleeding in middle ear. The cause of the profuse bleeding could not be confirmed; however, the radiological middle ear findings seem suspicious enough to be considered as a cause for the same. The upper respiratory infection probably precipitated acute dilatory Eustachian tube dysfunction, thus resulting in middle ear blood draining through the dilated Eustachian tube into the nasal cavity which was responsible for the epistaxis and post nasal trickle of blood. 
Control of upper respiratory infection with injectable antibiotics, antihistaminics, and decongestant nasal drops most probably led to resolution of epistaxis.

\section{CONCLUSION}

Epistaxis is the most common clinical presentation in the Department of Otolaryngology and the management of epistaxis is not very difficult. However, for those epistaxis of unknown origin and those having recurrent episodes, fatality may be high in case of massive bleeding. We described a rare cause of epistaxis secondary to otitis media and probable resultant acute dilatory Eustachian tube dysfunction.

\section{REFERENCES}

1. Santamaria, JP.; Abrunzo, TS. Ear, nose and throat disorders. In: Barkin RM, Caputo GL, Jaffee DM, Knapp JF, Schafermeyer RW, Seidel JS, editors. Pediatric emergency medicine: concepts and clinical practice. St. Louis (MO): Mosby-year Book Inc.; 1997. pp. 713-716.

2. Padgham N. Epistaxis: anatomical and clinical correlates. J Laryngol Otol 1990 Apr;104(4):308-311.

3. Jiakong, W.; Zhou, L.; Tang, A. Otolaryngology-head and neck surgery. Beijing: People's Medical Publishing House; 2010. pp. 303-306.
4. Bansal, M. Disease of external nose and epistaxis. Disease of ear, nose and throat. New Delhi: Jaypee Brothers Medical Publishers (P) Ltd.; 2013. pp. 289-297.

5. Thomas A Tami, James A Marrell. Ballengera's otorhinolaryngology head and neck surgery. Shelton (CT): People's Medical Publishing House; 2009. pp. 551-555.

6. Hough, JD.; McGee, MM. Otologic trauma. In: Paparella MM, Shumrick DA, editors. Otolaryngology. 3rd ed. Philadelphia (PA): WB Saunders; 1991. pp. 1137-1160.

7. Lalwani AK, Jackler RK. Spontaneous hemotympanum associated with chronic middle ear effusion. Am J Otol 1991 Nov;12(6):455-458.

8. Pulec JL, DeGuine C. Hemotympanum from trauma. Ear Nose Throat J 2001 Aug;80(8):486-487.

9. Evans TC, Hecker J, Zaiser DK. Hemotympanums secondary to spontaneous epistaxis. J Emerg Med 1988 Sep-Oct;6(5): 387-389.

10. McCurdy JA Jr. Effects of nasal packing on Eustachian tube function. Arch Otolaryngol 1977 Sep;103(9):521-523.

11. Bluestone, CD. Eustachian tube: structure, function, role in otitis media. New York: B C Decker; Introduction. 2005. pp. 1-9.

12. Schilder AG, Bhutta MF, Butler CC, Holy C, Levine LH, Kvaerner KJ, Norman G, Pennings RJ, Poe D, Silvola JT, et al. Eustachian tube dysfunction: consensus statement on definition, types, clinical presentation and diagnosis. Clin Otolaryngol 2015 Oct;40(5):407-411. 